\title{
Is there an excess in maternal transmission of NIDDM?
}

\author{
B.D. Mitchell ${ }^{1,2}$, C.M. Kammerer ${ }^{2}$, L. J. Reinhart ${ }^{1}$, M.P. Stern ${ }^{1}$, J. W. MacCluer ${ }^{2}$ \\ ${ }^{1}$ Division of Clinical Epidemiology, Department of Medicine, University of Texas Health Science Center, San Antonio, \\ Texas, USA \\ ${ }^{2}$ Department of Genetics, Southwest Foundation for Biomedical Research, San Antonio, Texas, USA
}

Summary Family studies have demonstrated that there is a strong genetic component to the aetiology of non-insulin-dependent diabetes mellitus (NIDDM), although the mode of inheritance is unknown. A number of recent family history studies, including one in Mexican Americans, have suggested that there is an excess of maternal transmission of NIDDM. Family history studies are subject to various types of bias, however, and the potential for bias in many of these studies has not been thoroughly evaluated. We therefore tested the hypothesis that diabetes is more likely to be transmitted from mothers than from fathers using data collected from a large family study of low-income Mexican Americans in San Antonio, Texas. The parents and offspring from 318 different nuclear families attended our medical clinic, where they received a 2 -h oral glucose test. Diabetes was diagnosed on the basis of
World Health Organization criteria. The sibships were classified into diabetic sibships (at least one sibling in the sibship was diabetic; $n=54$ ) and non-diabetic siblings (no diabetic siblings; $n=264$ ). The prevalence of diabetes among mothers of diabetic siblings was $61.4 \%$ (27 of 44 ) compared to $64.3 \%$ (18 of 28) among fathers of diabetic siblings (rate ratio $=0.95 ; 95 \%$ confidence interval: $0.51-1.84)$. For the non-diabetic sibships, the prevalence of diabetes was $31.7 \%$ (78 of 246) and $28.9 \%$ (37 of 128 ) among mothers and fathers, respectively (rate ratio $=1.09$; $95 \%$ confidence interval: $0.73-1.67)$. These data provide no evidence for an excess maternal transmission of diabetes in Mexican Americans. [Diabetologia (1995) 38: 314-317]

Key words NIDDM, family studies, inheritance, genetics, Mexican Americans.
Non-insulin-dependent diabetes mellitus (NIDDM) is a common chronic disease that affects $6-7 \%$ of adults in the United States [1]. The disease is diagnosed on the basis of elevated blood glucose levels and disease onset generally occurs in the fifth or sixth decade. Defects in both insulin sensitivity and insulin secretion are present in affected individuals, although the processes leading up to these abnormalities have not yet been clearly defined. One of the

Received: 26 April 1994 and in revised form: 1 July 1994

Corresponding author: B. Mitchell, Ph.D., Department of Genetics, Southwest Foundation for Biomedical Research, P.O.Box 28147, San Antonio, TX 78228-0147, USA

Abbreviations: NIDDM, Non-insulin-dependent diabetes mellitus; OGTT, glucose tolerance test; IDDM, insulin-dependent diabetes strongest risk factors for NIDDM is a positive family history for the disease, although elevated body mass index and low levels of physical activity also contribute to risk of the disease.

Surveys conducted in a variety of populations have noted that individuals with NIDDM are more likely to report a history of diabetes in the mother than in the father [2-8]. These observations have inspired a number of hypotheses to explain how diabetes could be preferentially transmitted through the maternal line, ranging from a gestational effect of diabetes on the fetus [9-11] to maternal inheritance of diabetogenic genes through mitochondrial DNA $[12,13]$.

Prior to pursuing hypotheses to account for differences between parents in the transmission of NIDDM, experimental verification of parental differences in NIDDM transmission is required. Nearly 
all of the available data on differential transmission are based on reported history of diabetes in the parents. The possibility that these studies could reflect a differential awareness that individuals have of their mothers' and fathers' true diabetes status has not been adequately addressed.

We have also reported an excess maternal transmission of NIDDM in Mexican Americans residing in San Antonio, Texas [6]. This observation was made on the basis that NIDDM prevalence, as diagnosed by World Health Organization criteria, was significantly higher among individuals reporting that their mother had diabetes than in individuals reporting that their father had diabetes. From this same population, we have now obtained a sample of 319 nuclear families and performed glucose tolerance tests on family members to diagnose diabetes. In the present paper we report that there is essentially no difference in diabetes prevalence between the mothers and fathers of diabetic offspring, nor between the mothers and fathers of non-diabetic offspring.

\section{Subjects and methods}

Study subjects. Families were identified to represent a sample of families from a low-income neighbourhood (barrio) in San Antonio, Texas. Two sets of probands were identified: one set ascertained without regard to their disease status (randomly ascertained probands; $n=33$ ) and one set ascertained because they had been previously diagnosed with NIDDM in a population-based survey [14] (diabetic probands; $n=29$ ). All first, second, and third degree relatives of the randomly ascertained and diabetic probands aged 16 years and over were invited to receive a medical examination at our medical clinic.

From the 62 extended pedigrees, a total of 318 sibships were identified in which at least one parent and one child were examined for diabetes. For purposes of the analyses presented in this report, the unit of analysis is a sibship. We defined a diabetic sibship as one in which diabetes was present in one or more siblings and a non-diabetic sibship as one in which diabetes was not present in any sibling. There were a total of 54 diabetic and 264 non-diabetic sibships in which at least one parent had been examined.

Diagnosis of diabetes. Participating subjects were invited to at tend a medical clinic, where they received a medical history interview, a brief physical examination, and a $2-\mathrm{h}$ oral glucose tolerance test. Blood samples were drawn, following a 12-h fast, for measurement of plasma glucose, and a second sample was drawn $2 \mathrm{~h}$ after ingestion of a 75-g glucose-equivalent load (Orangedex; Custom Laboratories, Baltimore, Md., USA). Plasma glucose concentrations were measured using an Abbott VP System (Abbott Laboratories, South Pasadena, Calif., USA), and diabetes was diagnosed according to the World Health Organization plasma glucose criteria (fasting plasma glucose $\geq 7.8 \mathrm{mmol} / \mathrm{L}(140 \mathrm{mg} / \mathrm{dl})$ or 2 -h plasma glucose $\geq 11.1 \mathrm{mmol} / \mathrm{L}(200 \mathrm{mg} / \mathrm{dl})$ [15]. Subjects reporting that they were currently taking antidiabetic medications were also considered to have diabetes. Diabetic subjects on insulin therapy were excluded from the analysis if their age of onset was less than 30 years or if their age of onset was less than 40 years and their body mass index was less than $30 \mathrm{~kg} / \mathrm{m}^{2}$,
Table 1. Number of sibships according to number of parents examined

\begin{tabular}{lll}
\hline & $\begin{array}{l}\text { Diabetic } \\
\text { sibships }^{\text {a }}\end{array}$ & $\begin{array}{l}\text { Non-diabetic } \\
\text { sibships }\end{array}$ \\
\hline Number of sibships & 54 & 264 \\
Mother only examined & 26 & 135 \\
Father only examined & 10 & 18 \\
Both parents examined & 18 & 111 \\
\hline
\end{tabular}

a Sibship, diabetic if 1 or more siblings has diabetes; sibship, non-diabetic if no siblings have diabetes

since such individuals were considered to have possible insulin-dependent diabetes.

\section{Statistical methods}

The "excess maternal transmission" hypothesis would predict that mothers of diabetic subjects would be more likely to have diabetes than fathers of diabetic subjects. To test this hypothesis we compared the prevalence of diabetes between mothers and fathers of diabetic sibships using the chi-square test. As a control, we also compared diabetes prevalence between mothers and fathers of non-diabetic sibships. Exact binomial confidence intervals were computed around the rate ratios [16].

\section{Results}

Table 1 shows the number of diabetic and non-diabetic sibships according to the number of parents who were tested for diabetes. The mother was examined in 44 of the 54 diabetic sibships $(81.5 \%)$, while the father was examined in 28 of them $(51.8 \%)$. Of the 10 unexamined mothers, eight were deceased, one could not be located, and one refused our invitation to participate in the study. Of the 26 unexamined fathers, 17 were deceased, five could not be located, and the remaining four refused our invitation to participate. Thus, $75.7 \%$ of the living fathers ( 28 of 37 ) and $95.3 \%$ of the living mothers (44 of 46 ) were examined. In the 264 non-diabetic sibships, 246 of the mothers were examined (93.2\%) compared to 128 of the fathers $(48.5 \%)$.

Clinical characteristics of the diabetic subjects are shown in Table 2. There were 54 diabetic offspring, 105 diabetic mothers ( 27 having diabetic offspring), and 55 diabetic fathers (18 having diabetic offspring). The mean age at diagnosis was 41.8 years in the offspring, compared to 52.1 years and 53.6 years, respectively, in the diabetic mothers and fathers. Slightly more than $60 \%$ of the diabetic parents were taking antidiabetic medications, compared to approximately $51 \%$ of the diabetic offspring. Diabetic mothers were somewhat more likely to be taking insulin than diabetic fathers, although this difference was not statistically significant $\left(\mathrm{X}_{3}^{2}=5.72 ; p=0.06\right)$.

The prevalence of NIDDM among the parents of the diabetic and non-diabetic sibships is shown in Table 3. Among the diabetic sibships, the prevalence of 
Table 2. Clinical characteristics of diabetic subjects

\begin{tabular}{|c|c|c|c|}
\hline & Diabetic offspring & Diabetic mothers & Diabetic fathers \\
\hline$n$ & $\overline{54}$ & $\overline{105}$ & $\overline{55}$ \\
\hline Current age (years) & $45.2 \pm 11.3^{\mathrm{a}}$ & $59.4 \pm 12.3$ & $61.2 \pm 11.6$ \\
\hline Body mass index $\left(\mathrm{kg} / \mathrm{m}^{2}\right)$ & $32.7 \pm 6.7$ & $32.1 \pm 6.8$ & $31.0 \pm 5.8$ \\
\hline Age at diagnosis (years) & $40.8 \pm 10.9$ & $52.1 \pm 12.1$ & $53.6 \pm 13.6$ \\
\hline$\%$ newly diagnosed & $43 \%(23)^{b}$ & $30 \%(32)$ & $31 \%(17)$ \\
\hline \multicolumn{4}{|l|}{ Current treatments } \\
\hline$\%$ tablets & $35 \%(19)$ & $39 \%(41)$ & $53 \%(29)$ \\
\hline$\%$ insulin & $15 \%(8)$ & $24 \%(25)$ & $9 \% \quad(5)$ \\
\hline
\end{tabular}

${ }^{\mathrm{a}}$ Mean \pm standard deviation; ${ }^{\mathrm{b}}$ number affected in parentheses

Table 3. Prevalence of NIDDM in mothers and fathers of offspring with and without diabetes

\begin{tabular}{lclllll}
\hline \multirow{2}{*}{$\begin{array}{l}\text { Offspring } \\
\text { status }\end{array}$} & \multirow{2}{*}{$\begin{array}{l}\text { Number of } \\
\text { sibships }\end{array}$} & \multicolumn{2}{l}{ Mothers } & \multicolumn{2}{l}{ Fathers } \\
\cline { 3 - 4 } \cline { 6 - 7 } & & $\%$ & $n$ & & $\%$ & $n$ \\
\hline Diabetic & 54 & 61.4 & $(27 / 44)$ & & 64.3 & $(18 / 28)$ \\
Non-diabetic & 264 & 31.7 & $(78 / 246)$ & & 28.9 & $(37 / 128)$ \\
\hline
\end{tabular}

Rate ratios (mothers/fathers):

diabetic offspring: $\mathrm{RR}=61.4 / 64.3=0.95$

$95 \%$ confidence interval: $0.51-1.84$

non-diabetic offspring: $\mathrm{RR}=31.7 / 28.9=1.09$

95\% confidence interval: $0.73-1.67$

diabetes in the mothers was $61.4 \%$ ( 27 of 44$)$, while the prevalence in the fathers was $64.3 \%$ (18 of 28 ), indicating that mothers were 0.95 times as likely to have diabetes as the fathers $(95 \%$ confidence interval: $0.51-1.84: \mathrm{X}^{2}=0.06 ; p=0.81$ ). Among the nondiabetic sibships, the corresponding prevalence rates of diabetes were $31.7 \%$ ( 78 of 246 ) and $28.9 \%$ (37 of $128)$, corresponding to a rate ratio of 1.09 (95\% confidence interval: $\left.0.73-1.67 ; \mathrm{X}^{2}=0.31 ; p=0.58\right)$.

\section{Discussion}

Studies performed in several populations have suggested a marked excess in mother-to-offspring transmission of NIDDM. Alcolado and Alcolado [3] assessed the parental diabetes history in NIDDM patients in Britain and found that $36 \%$ of mothers were affected compared to only $15 \%$ of the fathers. These results were nearly identical to those obtained from 536 NIDDM patients in the French CODIAB study, where a history of diabetes was present in $33.0 \%$ of the mothers of NIDDM patients compared to only $17.1 \%$ in the fathers [4]. An excess of maternal transmission of diabetes has also been reported in several other populations [4-7], including Hispanics $[6,7]$ and Chinese [5]. In the National Health and Nutrition Survey (NHANES II), a maternal history of diabetes was significantly associated with fasting glucose levels in women, although in men, a history of diabetes in siblings was a stronger predictor [8].
It has been postulated that mothers with diabetes during their pregnancy have an increased likelihood of transmitting diabetes on to their offspring. The "fuel-mediated teratogenesis" hypothesis, first proposed by Freinkel [17], posits that fetal development is compromised during the diabetic pregnancy in such a way that pancreatic beta cells are unable in later life to respond adequately to the challenges posed by insulin resistance. Considerable epidemiologic evidence supports this hypothesis, including the fact that offspring of diabetic pregnancies tend to be more obese and more glucose intolerant compared to age- and sex-matched control subjects [9-10] and that diabetes prevalence is higher in the offspring of mothers who were diabetic during their pregnancy than in offspring of mothers who became diabetic after their pregnancy [11].

Given the relatively late onset of NIDDM, it seems unlikely that diabetes during the pregnancy could account for the large excesses in maternal transmission of NIDDM reported in some populations. Although the prevalence of gestational diabetes per se was not assessed in the San Antonio Heart Study, only $5.3 \%$ of women and $4.3 \%$ of men between the ages of 25 and 45 years, i. e., the childbearing years, had diabetes [18]. In populations such as the Pima Indians, where diabetes occurs at younger ages, diabetes during pregnancy could account for a larger proportion of maternal transmission.

Other explanations for increased maternal transmission of diabetes have been proposed. Maternal inheritance of diabetes associated with mutations in mitochondrial DNA have been reported $[12,13,19,20]$. In most of these cases, however, diabetes tends to be transmitted as part of a broader syndrome, and it seems unlikely that this mechanism plays a large role in the intergenerational transmission of NIDDM. Environmental factors may also play a role since mothers may be more likely than fathers to pass diabetes risk factors on to their children.

The possibility that biased reporting may produce a spurious excess in maternal transmission of NIDDM has not been adequately evaluated. Reporting bias is a major concern in family history studies 
since individuals may be more likely to know about their mothers' health status than their fathers'. A second concern is that, since women utilize health care services more than men, more fathers may have had undetected diabetes. Finally, fathers of diabetic subjects may be more likely than mothers to die of insulin resistance-associated cardiovascular disease before either the clinical onset or diagnosis of NIDDM.

A limitation of the present study is that not all parents could be examined. If diabetic fathers were more likely to participate than non-diabetic fathers, then the prevalence of diabetes in the fathers would have been overestimated and a "true" maternal excess in diabetes would have been obscured. Approximately $50 \%$ of the fathers of diabetic and non-diabetic sibships were examined compared to $81 \%$ and $93 \%$, respectively, of mothers of diabetic and non-diabetic sibships. The examination rates among living parents of diabetic sibships, however, was $76 \%$ for fathers and $96 \%$ for mothers. Seventeen of the 26 unexamined fathers were deceased. Because diabetes is associated with increased mortality, it is likely that we have underestimated, rather than overestimated, the true prevalence of diabetes in fathers. (It should be noted, however, that the "true" prevalence of diabetes in the mothers may also have been underestimated since 8 of the 10 unexamined mothers were also deceased). These limitations notwithstanding, the response bias associated with the present study may be less than the potential reporting bias of other study designs in which parental diabetes status is determined by a history of diabetes as provided by the offspring.

In conclusion, the data presented in this report suggest that in at least some of the previous studies reporting an excess of maternal transmission of diabetes, the apparent excess could be attributed to reporting bias. In the San Antonio Heart Study, which represents the same population from which families for the present study were sampled, the prevalence of diabetes was higher in subjects who reported a diabetic mother than in those who reported a diabetic father, although subanalyses of these data suggested that motherdaughter transmission was more common than mother-son transmission [5]. On the other hand, when both parents and their offspring were actually tested for diabetes, no evidence for parental differences in the transmission of NIDDM is observed.

Acknowledgements. This research was supported by National Institutes of Health grants PO1-HL45 522 and RO1-DK42273.

\section{References}

1. Harris MI, Hadden WC, Knowler WC, Bennett PH (1987) Prevalence of diabetes and impaired glucose tolerance and plasma glucose levels in U.S. population aged $20-74$ yr. Diabetes 36: 523-534

2. Martin AO, Simpson JL, Ober C, Freinkel N (1985) Frequency of diabetes mellitus in mothers of probands with gestational diabetes: possible maternal influence on the predisposition to gestational diabetes. Am J Obstet Gynecol 151: 471-475

3. Alcolado JC, Alcolado R (1991) Importance of maternal history of non-insulin-dependent diabetic patients. BMJ 302: 1178-1180

4. Thomas F, Balkau B, Vauzelle-Kervroedan F, Papoz L, and the CODIAB Study Group (1994) Maternal effect and familial aggregation in NIDDM. Diabetes 43: 63-67

5. Yang NP, Lee SY, Chou P (1990) Community-based epidemiological study on hypertension and diabetes - community-based preventive medicine by Yang-Ming Crusade in 1989. Chung Hua I Hsueh Tsa Chih (Taipei) 46: 134-146

6. Mitchell BD, Valdez RA, Hazuda HP, Haffner SM, Stern MP (1993) Differences in the prevalence of diabetes and impaired glucose tolerance according to maternal or paternal history of diabetes. Diab Care 16: 1262-1267

7. Scheuner MT, Wang S-J, Raffel LJ, Vadheim CM, Ipp E, Rotter JI (1993) Maternal transmission of the insulin resistance syndrome (IRS) in familial Hispanic noninsulin dependent diabetes (NIDDM). Am J Hum Gen 53: A502 (Abstract)

8. Harlan LC, Harlan WR, Landis JR, Goldstein NG (1987) Factors associated with glucose tolerance in adults in the United States. Am J Epidemiol 126: 674-684

9. Pettitt DJ, Baird HR, Aleck KA, Bennett PH, Knowler WC (1983) Excessive obesity in offspring of Pima Indian women with diabetes during pregnancy. N Eng J Med 308: 242-245

10. Silverman BL, Rizzo T, Green OC et al. (1991) Long-term prospective evaluation of offspring of diabetic mothers. Diabetes 40[Suppl 2]: 121-125

11. Pettitt DJ, Aleck KA, Baird HR, Carraher MJ, Bennett PH, Knowler WC (1988) Congenital susceptibility to NIDDM: role of intrauterine environment. Diabetes 37:622-628

12. Ballinger SW, Shoffner JM, Hedaya EV, Trounce I, Polak MA, Koontz DA, Wallace DC (1992) Maternally transmitted diabetes and deafness associated with a $10.4 \mathrm{~kb}$ mitochondrial DNA deletion. Nature Genet 1: 11-15

13. Reardon W, Ross RJW, Sweeny MG, Luxon LM, Pembrey ME, Harding AE, Trembath RC (1992) Diabetes mellitus associated with a pathogenic point mutation in mitochondrial DNA. Lancet 340: 1376-1379

14. Mitchell BD, Kammerer CM, Reinhart LJ, Stern MP (1994) NIDDM in Mexican American families: heterogeneity by age of onset. Diab Care 17: 567-573

15. World Health Organization Expert Committee (1980) Second report on diabetes mellitus. Geneva, Switzerland: World Health Organization. Technical Report Series, No. 646

16. Guess HA, Lydick EG, Small RD, Miller LP (1987) Exact binomial confidence intervals for the relative risk in follow-up studies with sparsely stratified incidence density data. Am J Epidemiol 125: 340-347

17. Freinkel N (1980) Of pregnancy and progeny. Diabetes 29: 1023-1039

18. Mitchell BD, Stern MP, Haffner SM, Hazuda HP, Patterson JK (1990) Risk factors for cardiovascular mortality in Mexican Americans and non-Hispanic whites: the San Antonio Heart Study. Am J Epidemiol 131: 423-433

19. Remes AM, Majamaa K, Herva R, Hassinen IE (1993) Adult-onset diabetes mellitus and neurosensory hearing loss in maternal relatives of MELAS patients in a family with the tRNA (Leu (UUR)) mutation. Neurology 43: 1015-1020

20. Rotig A, Bessis JL, Romero N et al. (1992) Maternally inherited duplication of the mitochondrial genome in a syndrome of proximal tubolopathy, diabetes mellitus, and cerebellar ataxia. Am J Hum Genet 50: 364-370 